\section{An investigation of antibiotic prophylaxis in implant practice in the UK}

\author{
R. S. Ireland, ${ }^{1}$ N. O. Palmer, ${ }^{2}$ A. Lindenmeyer ${ }^{3}$ and N. Mills ${ }^{4}$
}

VERIFIABLE CPD PAPER

IN BRIEF
- Suggests that there is currently a wide
variation in prescribing patterns for
antibiotic prophylaxis when placing
dental implants.
Reports that the evidence for using
prophylactic antibiotics when placing
dental implants is weak.
Highlights the need for evidence-based
guidelines with respect to prophylactic
antibiotic prescribing when placing
dental implants.

\begin{abstract}
Background There is increasing evidence of the inappropriate use of antimicrobials in dentistry and this may contribute to the problem of antimicrobial resistance. The research to date with regard to efficacy of antimicrobial prophylaxis in reducing failure of integration and postoperative complications when placing dental implants remains equivocal. The aim of this study was to investigate how dentists in the UK use antimicrobials prophylactically in implant practice. Method An e-mail link was provided in 2011 to an anonymous online (Smart-Survey) questionnaire using three databases of dentists who, by being on them, had registered an interest in placing dental implants. Absolute frequencies were used to describe the study sample demographics and examine the distribution of responses for all the variables investigated. Results One hundred and nine completed questionnaires were received. Seventy-two percent $(n=76)$ routinely prescribed prophylactic antibiotics for all procedures. There was a wide variation in the pre-operative and postoperative prescription regimens with the majority (84\%) stating that it was to prevent infection at the site of surgery or to reduce a bacteraemia. Conclusions Although this was a small study with a low response rate, wide variations in antibiotic prescribing regimens with respect to drug, dose and duration were found. Further research is needed and guidelines developed to prevent antibiotic overprescribing and misuse.
\end{abstract}

\section{INTRODUCTION}

The loss of teeth for most patients can be an extremely upsetting and traumatic experience and the effects of denture wear on patients' well being and dental health are well documented. ${ }^{1}$ The development of osseointegrated implant therapy with the placing of implants as a restorative option for missing, heavily decayed or compromised teeth is now well established. With evidence of high and long-term success rates, ${ }^{2,3}$ there are increasing numbers of implant systems and increasing numbers of dentists and patients showing an interest in this field of dentistry. ${ }^{4,5}$ However, despite high success rates there are a number of complications that are associated with their provision. Failure of implants can occur and be distressing for both

${ }^{1 *}$ Warwick Dentistry, The University of Warwick,

Coventry, CV4 7AL; ${ }^{2} \mathrm{NHS}$ North West Mersey Deanery, Liverpool,L3 4BL; ${ }^{3-4}$ Warwick Dentistry, The University of Warwick, Coventry, CV4 7AL

${ }^{*}$ Correspondence to: Professor Robert Ireland

Email: R.Ireland@warwick.ac.uk

\section{Refereed Paper}

Accepted 6 July 2012

DOI: 10.1038/sj.bdj.2012.960

${ }^{\circ}$ British Dental Journal 2012; 213: E14 patient and clinician and as such all possible measures should be taken to minimise failure. Failure is categorised as either early or late, with early failure associated with many factors including failure of integration due to infection at the operating site and poor quality and quantity of bone. Infection has also been implicated in late implant failure. ${ }^{6,7}$ With infection associated with early failure of implants, researchers in the field and manufacturers of implants have suggested a number of different protocols for antimicrobial prophylaxis when implants are placed..$^{8-12}$ The benefits of prescribing antimicrobials are, however, limited by a number of problems associated with their use for example, side effects, allergic reactions, toxicity and more importantly the development of resistant strains of microbes. ${ }^{13}$ Within the last few decades, antimicrobial resistance has become a worldwide problem and constitutes a major threat to public health. ${ }^{14}$ There is increasing evidence of the inappropriate use of antimicrobials in dentistry and this may contribute to the problem of antimicrobial resistance. ${ }^{15-17}$ The use of antimicrobials leads to selection and dominance of resistant microorganisms; they can also increase the incidence of resistance through the exchange of genetic material, so that resistant genes can spread between bacterial populations. As a result antimicrobial prophylaxis remains a contentious issue in all surgical fields and medical specialities. It has been suggested that antibiotic prophylaxis for routine dental implant surgery offers no advantage for the patient. ${ }^{12}$ In minor oral surgery there is no evidence for the prophylactic use of antimicrobials to prevent postoperative infection in healthy patients as a result of surgical removal of impacted teeth or roots. ${ }^{18}$ Conversely, evidence exists that prophylactic use of antimicrobials has no effect on postoperative pain, swelling, infection or wound healing. ${ }^{19,20}$ The research to date with regard to efficacy of antimicrobial prophylaxis in reducing failure of integration of implants and reducing postoperative complications remains equivocal. ${ }^{8,21,22}$

The General Dental Council (GDC) has stated that 'a UK-qualified dentist would not be expected to be competent to practise implant dentistry without undertaking 
structured postgraduate training and assessment of competence.23 The GDC supports the Training standards in implant dentistry, published by the Faculty of General Dental Practice (UK) ${ }^{24}$ and expects education providers, and dentists who wish to practise implant dentistry, to refer to these standards as the authoritative source of training standards for implant dentistry for dentists in the UK. Dentists can access a number of implant courses which vary from weekend didactic courses, courses sponsored by implant manufacturers, certificate courses from non-registered academic institutions where there is no competency assessment, to diploma or masters taught programmes from academic institutions where there is an assessment of competency to successfully complete the programme. In spite of the wide range of training available, there is a lack of good evidence-based guidelines for dentists to refer to and no previous research investigating the use of antimicrobials in implant practice within the UK. A Canadian study concluded that the long-term prophylactic antibiotic use in implant surgery had no benefit over a pre-operative single dose antibiotic regimen. ${ }^{25}$ The aims of this study therefore, were to investigate how dentists in the UK use antimicrobials prophylactically in implant practice with specific reference to the implant procedures they are used for and the antimicrobial regimen adopted.

\section{METHOD}

The methodology consisted of an online anonymous questionnaire using SmartSurvey ${ }^{\mathrm{TM}}$ (http://www.smart-survey.co.uk/) of a sample of dentists practising in the UK who were likely to be placing implants, capturing both quantitative and qualitative data. The questionnaire was open online during November and December 2011 and consisted of four sections. The first section investigated the demographics of the sample including training in implant placement. The second section comprised a series of questions investigating implant procedures performed and implant systems used by the respondents. The third part investigated procedures for which antimicrobial prophylaxis were prescribed, the antimicrobial regimen used both for patients allergic and non-allergic to penicillin. The final sections investigated whether there were any pre-existing medical or dental conditions which meant there was a predisposition to use antimicrobial prophylaxis and the respondents' perceived reasons for prescribing antimicrobial prophylaxis when placing implants, such as circulating bacteraemia.

A convenience sample was obtained from the University of Warwick and the Faculty of General Dental Practice (FGDP) databases of current and past implantology students and the membership of the British Society of Periodontology and the British Dental Association (BDA). Dentists were invited to participate via e-mail enclosing a web link to the online questionnaire. The research questionnaire was piloted before the development of the definitive questionnaire and was approved by the University of Warwick Biomedical Ethics Research Committee.

The e-mail link was circulated to all those on the database and the resulting anonymised data, collected during November and December 2011, were exported into a statistical software package (IBM SPSS v.19). Absolute frequencies were used to describe the study sample demographics and examine the distribution of responses for all the variables investigated.

\section{RESULTS}

There were 109 completed questionnaires of which $85 \%$ were male $(n=93)$ and $15 \%$ female $(n=16)$ and of whom the majority practised in either general practice (56\%) or specialist practice (27\%).

Of the commercial implant systems used, there was a broad spectrum, although Astra tech Ankylos, Straumann, Nobel Biocare and Biohorizons were the most popular (Table 1); some respondents used more than one system.

Seventy-two percent $(n=76)$ routinely prescribed prophylactic antibiotics for all procedures. For patients not allergic to penicillin, $14.7 \%(\mathrm{n}=16)$ of the sample did not routinely prescribe antibiotics preoperatively. Almost half the sample (49.5\% $\mathrm{n}=54$ ) routinely prescribed $3 \mathrm{~g}$ amoxicillin one hour pre-operatively and the remaining $34.9 \%(n=39)$ prescribed a variety of antibiotics (Table 2) for a period of time varying between one and seven days.

For patients not allergic to penicillin, $22.5 \%$ of the sample did not prescribe
Table 1 Implant systems used $(n=109)$

\begin{tabular}{l|l}
\hline Make & Percentage (n) \\
\hline Astra tech Ankylos & $43.4(56)$ \\
\hline Straumann & $15.5(20)$ \\
\hline Nobel Biocare & $11.6(15)$ \\
\hline Biohorizons & $6.2(8)$ \\
\hline Biomet 3i & $5.4(7)$ \\
\hline Other & $17.9(23)$ \\
\hline
\end{tabular}

Table 2 The antibiotic routinely used preoperatively for patients not allergic to penicillin $(n=109)$

\begin{tabular}{l|l}
\hline Antibiotic & Percentage (n) \\
\hline Amoxicillin & $77.1(64)$ \\
\hline Clindamycin & $2.6(3)$ \\
\hline Augmentin & $2.6(3)$ \\
\hline Metronidazole & $0.9(1)$ \\
\hline Primcillin & $0.9(1)$ \\
\hline Dalacin C & $0.9(1)$ \\
\hline None & $14.7(16)$
\end{tabular}

Table 3 Prescribing regime for respondents using antibiotics postoperatively for patients not allergic to penicillin $(n=102)$

\begin{tabular}{|l|l|}
\hline Antibiotic regime & Percentage $(\mathrm{n})$ \\
\hline $\begin{array}{l}500 \mathrm{mg} \text { Amoxicillin } 3 \text { times } \\
\text { daily for } 7 \text { days }\end{array}$ & $9.8(10)$ \\
\hline $\begin{array}{l}500 \mathrm{mg} \text { Amoxicillin } 3 \text { times } \\
\text { daily for } 5 \text { days }\end{array}$ & $18.6(19)$ \\
\hline $\begin{array}{l}250 \mathrm{mg} \text { Amoxicillin } 3 \text { times } \\
\text { daily for } 7 \text { days }\end{array}$ & $16.7(17)$ \\
\hline $\begin{array}{l}250 \mathrm{mg} \text { Amoxicillin } 3 \text { times } \\
\text { daily for } 5 \text { days }\end{array}$ & $10.8(11)$ \\
\hline Other & $21.6(22)$ \\
\hline None & $22.5(23)$ \\
\hline
\end{tabular}

antibiotics routinely postoperatively but of those who did, 28.4\% ( $\mathrm{n}=29$ ) prescribed $500 \mathrm{mg}$ amoxicillin for either five or seven days (Table 3), 27.5\% ( $\mathrm{n}=28$ ) prescribed only $250 \mathrm{mg}$ for either five or seven days and the remaining 21.6\% ( $\mathrm{n}=22$ ) prescribed a range of antibiotics (augmentin, metronidazole, primcillin, cefuroxime, dalacin C) for periods of two to seven days.

Although 15.4\% $(\mathrm{n}=16)$ did not prescribe antibiotics routinely preoperatively for patients allergic to penicillin, of those who did 43.3\% ( $\mathrm{n}=45)$ prescribed 


\begin{tabular}{l|l|}
$\begin{array}{l}\text { Table } 4 \text { Prescribing regime for respondents } \\
\text { using antibiotics pre-operatively for } \\
\text { patients allergic to penicillin ( }=104)\end{array}$ \\
\hline $\begin{array}{l}\text { Antibiotic regime } \\
600 \mathrm{mg} \text { Clindamycin } 1 \text { hour } \\
\text { before }\end{array}$ & $43.3(45)$ \\
\hline $\begin{array}{l}400 \mathrm{mg} \text { Metronidazole } \\
3 \text { times daily for } 7 \text { days }\end{array}$ & $12.5(13)$ \\
\hline $\begin{array}{l}200 \mathrm{mg} \text { Metronidazole } \\
3 \text { times daily for } 7 \text { days }\end{array}$ & $6.7(7)$ \\
\hline $\begin{array}{l}300 \mathrm{mg} \text { Clindamycin } 1 \text { hour } \\
\text { before }\end{array}$ & $4.8(5)$ \\
\hline $\begin{array}{l}500 \mathrm{mg} \text { Erythromycin } 1 \text { hour } \\
\text { before }\end{array}$ & $4.8(5)$ \\
\hline Other & $12.5(13)$ \\
\hline None & $15.4(16)$ \\
\hline
\end{tabular}

Table 5 Prescribing regime for respondents using antibiotics post-operatively for patients allergic to penicillin $(n=100)$

\begin{tabular}{|l|l|}
\hline Antibiotic regi me & Percentage (n) \\
\hline $\begin{array}{l}200 \mathrm{mg} \text { Metronidazole } \\
3 \text { times daily for } 7 \text { days }\end{array}$ & $10.0(10)$ \\
\hline $\begin{array}{l}400 \mathrm{mg} \text { Metronidazole } \\
3 \text { times daily for } 5 \text { days }\end{array}$ & $10.0(10)$ \\
\hline $\begin{array}{l}250 \mathrm{mg} \text { Erythromycin } 4 \text { times } \\
\text { daily for } 5 \text { days }\end{array}$ & $9.0(9)$ \\
\hline $\begin{array}{l}200 \mathrm{mg} \text { Metronidazole } \\
3 \text { times daily for } 5 \text { days }\end{array}$ & $5.0(5)$ \\
\hline $\begin{array}{l}250 \mathrm{mg} \text { Erythromycin } 4 \text { times } \\
\text { daily for } 7 \text { days }\end{array}$ & $5.0(5)$ \\
\hline Other & $48.0(48)$ \\
\hline None & $13.0(13)$ \\
\hline
\end{tabular}

$600 \mathrm{mg}$ clindamycin one hour before the procedure, $12.5 \%(\mathrm{n}=13)$ prescribed $400 \mathrm{mg}$ metronidazole three times daily for seven days; $6.7 \%(n=7)$ prescribed $200 \mathrm{mg}$ metronidazole three times daily for seven days; 4.8\% ( $\mathrm{n}=5)$ prescribed $300 \mathrm{mg}$ clindamycin one hour before the procedure; $4.8 \%(\mathrm{n}=5)$ prescribed $500 \mathrm{mg}$ erythromycin one hour before the procedure and the remaining $12.5 \%(n=13)$ prescribed varying dosages of clindamycin, metronidazole, erythromycin, septomycin, doxycycline, clarithromycin, macrolides or rhodogyl (Table 4).

Although 13\% (n = 13) did not prescribe antibiotics routinely postoperatively for patients who are allergic to penicillin (Table 5), of those who did, 10\% $(n=10)$ prescribed $200 \mathrm{mg}$ metronidazole three times daily for seven days; $10 \%(n=10)$ prescribed $400 \mathrm{mg}$ three times daily for five days; 9\% $(\mathrm{n}=9)$ prescribed $250 \mathrm{mg}$ erythromycin four times daily for five days;

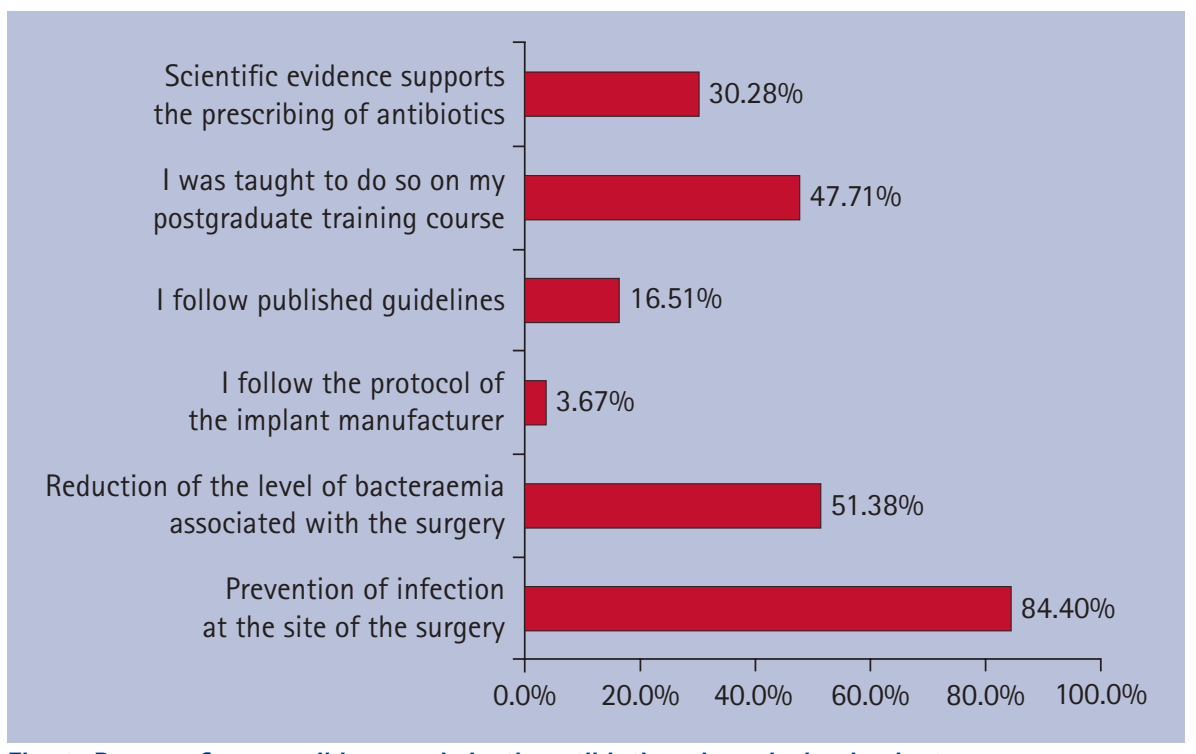

Fig. 1 Reasons for prescribing prophylactic antibiotics when placing implants

5\% ( $=5)$ prescribed $200 \mathrm{mg}$ metronidazole three times daily for five days; $5 \%$ $(n=5)$ prescribed metronidazole four times daily for seven days. The remaining $48 \%$ ( $n=48$ ) largely prescribed metronidazole, clindamycin or erythromycin for a wide range of varying dosages for periods of one to seven days.

When asked the reasons for prescribing prophylactic antibiotics (Fig. 1), many respondents gave more than one reason but the majority stated that it was to prevent infection at the site of surgery (84.4\%: $n=92$ ) or to reduce the level of bacteraemia (51.4\%: $n=56)$. Almost half the respondents stated that they had been taught to do so in their postgraduate training course.

However, 53\% ( $\mathrm{n}=58)$ said that their prescribing regime would be influenced by underlying medical conditions such as diabetes, warfarin, bisphosphonates, cardiac problems, immuno-compromised patients or if advised to do so by a medical specialist. With respect to oral inflammation, 44\% ( $\mathrm{n}=48)$ would place implants where there was existing periodontal disease, $43 \%(n=47)$ where there was chronic infection and $11 \%(n=12)$ where there was acute infection.

\section{DISCUSSION}

At the present time there is no requirement to be on a specialist list to place implants and as such there was not an easily identifiable sample for the investigation. An attempt to obtain customer lists from implant manufacturers was unsuccessful so the study relied on a convenience sample based on the databases of current and past students of the University of Warwick and the Faculty of General Dental Practitioners UK, both recognised providers of implant training, as well as the British Society of Periodontology and the BDA. Unfortunately, it is not possible to calculate the total number of dentists placing implants in the UK but the response rate in this study is considered to be low. The results therefore should be interpreted with considerable caution. Nevertheless, it does give an indication of the current lack of consensus with respect to prophylactic antibiotic prescribing for implant patients in the UK. In this study, 72\% routinely prescribed prophylactic antibiotics for all procedures of whom the majority (84\%) stated that this was for the prevention of infection (Fig. 1). This compares with 50\% reported in a similar study with implant practitioners in Jordan. ${ }^{26}$ Approximately 85\% of respondents reported routinely prescribing an antibiotic pre-operatively and almost 80\% postoperatively. The results in this study suggest a wide variation in prescribing patterns with respect to the choice of drug, the dose and the duration for both pre-operative and postoperative prescription (Tables 2-5). A recent systematic review ${ }^{27}$ concluded that there is some evidence suggesting that $2 \mathrm{~g}$ of amoxicillin given orally one hour pre-operatively is effective in reducing failures of dental implants placed in normal conditions. More specifically the review stated that giving antibiotics prophylactically to 
33 patients would prevent 1 patient experiencing an implant loss. In our study almost 50\% prescribed $3 \mathrm{~g}$ amoxicillin orally one hour preoperatively.

Antimicrobial prophylaxis remains a contentious issue in all surgical fields and medical specialities. The administration of antimicrobials should reduce morbidity and mortality but a number of ethical and medico-legal issues are involved in any decision to prescribe prophylactic antimicrobials; the 'at risk' group must be easily identifiable to prevent overuse, prophylaxis must be efficacious and reliable, proof of efficacy must be without question, prophylaxis must not cause more harm than the infection being prevented, bacteraemia to be prevented has to be the cause of patient disease or implant failure and the antimicrobial is only aimed at preventing infection by the causative pathogen.

Within this study over $50 \%$ of respondents stated that prophylaxis was required to prevent a bacteraemia leading to possible loss of implants. The scientific evidence for bacteraemias associated with dental procedures has been reviewed, specifically in relation to cardiac patients, and it has been concluded by the British Society for Antimicrobial Chemotherapy (BSAC) and the National Institute for Health and Clinical Excellence (NICE) that the magnitude and frequency of bacteraemias result from normal oral function for example, chewing and toothbrushing and not from dental procedures. ${ }^{28}$ In minor oral surgery there is no evidence for the prophylactic benefit of using antimicrobials to prevent postoperative infection in healthy patients as a result of the surgical removal of impacted teeth or roots. Conversely, evidence exists that the prophylactic use of antimicrobials in minor oral surgery has no effect on post operative pain, swelling, infection or wound healing. ${ }^{18,29}$ It is the view of the authors that this should include implants, assuming they are placed in an aseptic environment. It has been shown that antibiotics do not provide significant advantages concerning postoperative infections in the presence of good asepsis. ${ }^{11}$ Most respondents (79\%) placed implants using a sterile technique (gowns, masks, gloves, head covering, drapes, sterile instruments), 16\% used a barrier technique as for dento-alveolar surgery and 5\% operated under a surgically clean environment.

With regard to the placing of implants, researchers and teachers have promulgated a number of different protocols for antimicrobial prescribing when implants are placed. ${ }^{30}$ They have also suggested that their use reduces the incidence of postoperative infections, peri-implantitis and postoperative pain. This, however, remains a controversial issue with little high quality evidence to support the routine use of prophylactic antimicrobials in the placing of implants. A recent systematic review ${ }^{26}$ concluded that it is still unknown whether postoperative antibiotics are beneficial and which is the most effective antibiotic.

\section{CONCLUSIONS}

Although this was a small study with a low response rate, wide variations in antibiotic prescribing regimens with respect to types, dose and duration were found. There is a need for high quality research to establish whether antimicrobial prophylaxis for all dental procedures involving implants is necessary. Following this, the results need to be translated into guidelines that can be integrated into teaching at all levels and clinical practice.

1. Davis D M. The shift in the therapeutic paradigm osseointegration. J Prosthet Dent 1998; 79: 37-42.

2. Jung $R E_{1}$ Pjetursson $B E_{1}$ Glauser $R$, Zembic $A$ Zwahlen M, Lang N P. A systematic review of the five-year survival and complication rates of implant-supported single crowns. Clin Oral Implants Res 2008; 19: 119-130.

3. Goodacre C J, Kan J Y, Rungcharassaeng K. Clinical complications of osseointegrated implants. J Prosthet Dent 1999: 81: 537-552.

4. Narby $B$, Kronström $M$, Söderfeldt $B$, Palmqvist $S$. Changes in attitudes toward desire for implant treatment: a longitudinal study of a middle-aged and older Swedish population. Int J Prosthodont 2008; 21: 481-485.

5. Ng P C, Pow E H, Ching S H, Lo E C, Chow T W. Dental implant practice among Hong Kong general dental practitioners in 2004 and 2008. Implant Dent 2011; 20: 95-105.

6. Esposito M, Hirsch J M, Lekholm U, Thomsen P. Biological factors contributing to failures of osseointegrated oral implants. (II). Etiopathogenesis. Eur J Oral Sci 1998; 106: 721-764.

7. Alsaadi G, Quirynen $M$, Komárek $A$, van Steenberghe D. Impact of local and systemic factors on the incidence of oral implant failures, up to abutment connection. J Clin Periodontol 2007: 34: 610-617.

8. Mazzocchi A, Passi L, Moretti R. Retrospective analysis of 736 implants inserted without antibiotic therapy. J Oral Maxillofac Surg 2007; 65: 2321-2323.

9. Balevi B. Do preoperative antibiotics prevent dental implant complications? Evid Based Dent 2008; 9: $109-110$.

10. Sharaf B, Jandali-Rifai M, Susarla S M, Dodson T B. Do perioperative antibiotics decrease implant failure? J Oral Maxillofac Surg 2011; 69: 2345-2350.

11. Abu-Ta'a M, Quirynen $M$, Teughels $W$, van Steenberghe D. Asepsis during periodontal surgery involving oral implants and the usefulness of peri-operative antibiotics: a prospective, randomized, controlled clinical trial. J Clin Periodontol 2008; 35: 58-63.

12. Gynther G W, Kondell PA, Moberg LE, Heimdahl A. Dental implant installation without antibiotic prophylaxis. Oral Surg Oral Med Oral Pathol Oral Radiol Endod 1998; 85: 509-511.

13. Finch $R$ G. Adverse reactions to antibiotics. In Greenwood D (ed) Antimicrobial chemotherapy. 4th ed. pp 200-211. Oxford: Oxford University Press, 2000.

14. House of Lords Select Committee on Science and Technology. Seventh Report. Resistance to antibiotics and other antimicrobial agents. London, The Stationary Office 1998

15. Palmer N A, Pealing R, Ireland R S, Martin M V. A study of prophylactic antibiotic prescribing in National Health Service general dental practice in England. Br Dent J 2000; 189: 43-46.

16. Palmer N A, Pealing R, Ireland R S, Martin M V. A study of therapeutic antibiotic prescribing in National Health Service general dental practice in England. Br Dent J 2000; 188: 554-558.

17. Tulip D E, Palmer N O. A retrospective investigation of the clinical management of patients attending an out of hours dental clinic in Merseyside under the new NHS dental contract. Br Dent J 2008; 205: 659-664; discussion 648.

18. Happonen R P, Bäckström A C, Ylipaavalniemi P. Prophylactic use of phenoxymethylpenicillin and tinidazole in mandibular third molar surgery, a comparative placebo controlled clinical trial. $\mathrm{Br} J$ Oral Maxillofac Surg 1990; 28: 12-15.

19. Siddiqi A, Morkel J A, Zafar S. Antibiotic prophylaxis in third molar surgery: A randomized doubleblind placebo-controlled clinical trial using splitmouth technique. Int J Oral Maxillofac Surg 2010; 39: 107-114.

20. Hill M. No benefit from prophylactic antibiotics in third molar surgery. Evid Based Dent 2005; 6: 10.

21. Esposito M, Cannizzaro G, Bozzoli P et al. Effectiveness of prophylactic antibiotics at placement of dental implants: a pragmatic multicentre placebo-controlled randomised clinical trial. Eur J Oral Implantol 2010; 3: 135-143.

22. Laskin D M, Dent C D, Morris H F, Ochi S, Olson $J$ W. The influence of preoperative antibiotics on success of endosseous implants at 36 months. Ann Periodontol 2000; 5: 166-174.

23. General Dental Council. Implantology- policystatement. London: GDC. Online statement available at http://www.gdc-uk.org/Dentalprofessionals/ Standards/Pages/Implantology.aspx (accessed September 2012).

24. Faculty of General Dental Practice (UK), The Royal College of Surgeons of England. Training standards in implant dentistry. 2008. London: FGDP, 2008. Online article available at http://www.adi.org. uk/profession/mentor/training_stds_imp_dent_ guide_2008.pdf (accessed September 2012).

25. Binahmed A, Stoykewych A, Peterson L. Single preoperative dose versus long-term prophylactic antibiotic regimens in dental implant surgery. Int $J$ Oral Maxillofac Implants 2005; 20: 115-117.

26. Abukaraky A E, Afifeh K A, Khatib A A et al. Antibiotics prescribing practices in oral implantology among jordanian dentists. A cross sectional observational study. BMC Res Notes 2011; 4: 266

27. Esposito M, Worthington H V, Loli V, Coulthard $P$, Grusovin M G. Interventions for replacing missing teeth: antibiotics at dental implant placement to prevent complications. Cochrane Database Syst Rev 2010; 7: CD004152.

28. Gould F K, Elliott T S, Foweraker J et al. Guidelines for the prevention of endocarditis: report of the Working Party of the British Society for Antimicrobial Chemotherapy. J Antimicrob Chemother 2006; 57: 1035-1042.

29. Blum I R. Contemporary views on dry socket (alveolar osteitis): a clinical appraisal of standardization, aetiopathogenesis and management: a critical review. Int J Oral Maxillofac Surg 2002; 31: 309-317.

30. Resnik R R, Misch C, Prophylactic antibiotic regimens in oral implantology: rationale and protocol. Implant Dent 2008; 17: 142-150. 